ISSN: $2354-1431$

http://tckh.daihoctantrao.edu.vn/

\title{
Tăng cường quản lý công tác kiểm tra, đánh giá kết quả học tập nhằm nâng cao năng lực tự học của sinh viên
}

\section{Phạm Thị Thu Thủy ${ }^{a, *}$

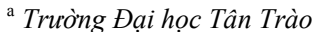 \\ *Email:thuykmn@gmail.com}

\section{Article info}

\section{Recieved:}

05/7/2017

Accepted:

$03 / 8 / 2017$

\begin{abstract}
Ability development is an important solution to improve the quality of training. Self-study ability is an important element, helping students achieve good results in learning. Therefore, in this article, the author mentions the solution: Strengthening the examination and evaluation of students' learning results in order to raise the student's self-learning ability.
\end{abstract}

Keywords:

Self-study ability;

Results evaluation;

Student.

\section{1. Đặt vấn đề}

Tự học là quá trình tự giác, tích cực độc lập chiếm lĩnh tri thức, hình thành kỹ năng, kỹ xảo của chính bản thân người học. Trong quá trình đó người học thực sự là chủ thể của quá trình nhận thức, nỗ lực huy động các chức năng tâm lý, tiến hành hoạt động nhận thức nhằm đạt được mục tiêu đã định. Tự học là "nội lực" quyết định chất lượng học tập, sáng tạo cho hôm nay và mai sau.

Năng lực tự học là những thuộc tính tâm lý nhờ chúng mà con người tự xử lý thông tin, các vấn đề được đặt ra trong học tập, trong cuộc sống nhằm biến tri thức của nhân loại thành sở hữu riêng của bản thân mình một cách hiệu quả nhất.

Kiểm tra, đánh giá là một khâu không thể thiếu trong quá trình đào tạo. Kiểm tra, đánh giá kết quả học tập của sinh viên là quá trình thu thập và xử lý thông tin về ý thức, trình độ và việc thực hiện nhiệm vụ, mục tiêu học tập của học sinh viên, về những tác động và nguyên nhân của thực trạng đó nhằm tạo cơ sở cho việc điều chỉnh phương pháp dạy và học.

Mục đích của kiểm tra, đánh giá là để thôi thúc tinh thần tích cực của học sinh trong học tập. Kiểm tra, đánh giá còn nhằm để tạo ra thông tin ngược từ người học trở lại người dạy. Thông qua kết quả kiểm tra, đánh giá biết được chỗ mạnh, yếu trong dạy và học đối với các bài học, môn học. Trên cơ sở đó, giảng viên sẽ điều chỉnh cách dạy và hướng dẫn sinh viên cách học cho phù hợp để quá trình giáo dục, đào tạo đạt kết quả tốt hơn.
Kinh nghiệm thực tiễn cho thấy: trường nào tổ chức tốt khâu kiểm tra, đánh giá thì ở trường đó sinh viên sẽ chủ động, tích cực, sáng tạo trong học tập, kết quả và năng lực tự học sẽ được nâng cao; còn trường nào tổ chức không tốt khâu kiểm, đánh giá thì ở đó sinh viên sẽ lười học, học thụ động, kết quả và năng lực tự học của sinh viên thấp.

Vì vậy, tăng cường công tác quản lý, tổ chức tốt công tác kiểm tra, đánh giá kêt quả học tập của sinh viên sẽ thúc đẩy quá trình tự học, dần hình thành thái độ nghiêm túc cũng như các kỹ năng tự học, phương pháp tự học và nâng cao được năng lực tự học cho sinh viên.

\section{Biện pháp tổ chức kiểm tra đánh giá}

\subsection{Tổ chức cho các bộ giáo viên nghiên cứu và hướng dẫn việc thực hiện qui chế thi, kiểm tra}

Việc tổ chức kiểm tra, thi phải được tổ chức theo đúng qui chế, vì vậy hàng năm Nhà trường, Khoa và các Tổ bộ môn cần tổ chức phổ biến, hướng dẫn cho giảng viên và sinh viên về việc thực hiện qui chế. Những quy định mới cần được triển khai kịp thời. Đặc biệt đối với những giảng viên trẻ; khoa, tổ chuyên môn cần hướng dẫn cho họ một cách cụ thể về việc thực hiện những qui chế này.

\section{2. Đổi mới hình thức, phương pháp kiểm tra đánh giá}

Đổi mới hình thức, phương pháp kiểm tra đánh giá kết quả học tập của sinh viên theo hướng:

- Chuyển từ đánh giá kiến thức, kỹ năng sang đánh giá năng lực của sinh viên cụ thể là: Đánh giá khả năng sinh viên vận dụng các kiến thức, kỹ năng, thái độ ở nhiều lĩnh 
vực vào giải quyết vấn đề thực tiễn công việc, thực tiễn cuộc sống; đánh giá được tiến hành trong mọi thời điểm của quá trình dạy học, chú trọng đến đánh giá trong khi học; bài tập đánh giá đặt trong tình huống, bối cảnh thực; đánh giá vì sự tiến bộ của sinh viên so với chính mình.

- Sử dụng nhiều hình thức kiểm tra đánh giá cụ thể như:

+ Đối với những bài kiểm tra điều kiện cần tăng cường hình thức kiểm tra miệng trước, trong, sau khi vào học bài mới, hoặc giao cho mỗi sinh viên một bài tập phải hoàn thành trong thời gian ngoài giờ lên lớp để đánh giá.

+ Đối với thi, kiểm tra học kỳ, học phần thì cần tăng cường hình thức thi trắc nghiệm, vấn đáp, thi thực hành. Đối với những môn không thể thi theo hình thức trắc nghiệm, vấn đáp hoặc thực hành thì tổ chức thi theo hình thức tự luận nhưng phải ra nhiều đề khác nhau để đảm bảo các sinh viên cạnh nhau phải làm những đề thi khác nhau. Đề thi tự luận nên ra theo hình thức mở để đánh giá năng lực vận dụng kiến thức, kỹ năng của sinh viên. Trong một chừng mực nhất định có thể giao những tiểu luận cho những sinh viên khá, giỏi làm để miễn thi.

Với các hình thức kiểm tra đánh giá trên sẽ góp phần đảm bảo cho kỳ thi nghiêm túc, đánh giá khách quan được kết quả học tập của sinh viên. Nhờ đó mà sinh viên sẽ có thái độ tự học nghiêm túc, phương pháp tự học hiệu quả hơn.

\section{3. Đổi mới, tăng cường quản lý công tác ra đề thi}

- Nội dung ra đề thi, kiểm tra phải được xác định là một trong những yếu tố quan trọng trong việc kiểm tra đánh giá chất lượng học tập của sinh viên. Vì vậy việc ra đề thi cần phải đảm bảo đúng yêu cầu và khoa học. Để khắc phục tình trạng thầy dạy, thầy ôn tập, thầy ra đề, thầy lại chấm thi; Nhà trường cần yêu cầu các khoa, tổ chuyên môn tổ chức soạn ngân hàng đề thi, hoặc cử nhiều giảng viên ra đề thi, trưởng khoa, trưởng bộ môn duyệt đề thi và bàn giao cho phòng Thanh tra - Khảo thí lựa chọn đề cho sinh viên thi. Cách ra đề thi này sẽ khắc phục được tình trạng sinh viên mời thầy ôn thi rồi học tủ những phần mà thầy "bật mí".

- Đề phải đảm bảo tính vừa sức, phù hợp với đối tượng, bởi vì nếu yêu cầu của đề quá dễ hoặc quá khó đều dẫn đến tình trạng không phân loại chính xác được trình độ của sinh viên, dẫn đến tình trạng thiếu hứng thú trong tự học.

- Nội dung đề thi phải gắn với nội dung tự học: Đề thi phải được soạn thảo dưới dạng buộc sinh viên phải sử dụng tổng hợp những tri thức, kỹ năng có được trong quá trình thực hiện các nhiệm vụ tự học vào giải quyết những vấn đề thực tiễn của cuộc sống. Do đó nếu sinh viên nào lười học, không thực hiện tốt nhiệm vụ tự học thì không thể làm tốt bài thi. Đề thi cần có các câu hỏi kiểm tra kiến thức cơ bản $(60 \%)$, vừa có những câu hỏi mở rộng vấn đề trên quan điểm vận dụng sáng tạo các các tài liệu, sách báo, các nội dung được trang bị trên lớp, các nội dung tự học ngoài giờ lên lớp để làm bài $(40 \%)$. Tránh cách ra đề nặng về trí nhớ, nhẹ về thực hành, học gì thi nấy, thầy ôn phần nào thi phần ấy nhằm tránh tình trạng quay cóp, gian lận trong thi cử, rèn ý thức độc lập, nghiêm túc khi làm bài.

\subsection{Tăng cường quản lý công tác coi thi, chấm thi}

- Coi thi nghiêm túc là một trong những cơ sở đảm bảo tính khách quan của công tác đánh giá kết qủa học tập của sinh viên. Để các kỳ thi được tổ chức một cách nghiêm túc, cần bố trí đủ bàn ghế cho mỗi thí sinh ngồi một bàn, đủ hai giám thị coi thi một phòng và tăng cường cán bộ giám sát các phòng thi; phát giấy nháp cho sinh viên tham dự kỳ thi; cương quyết xử lý những cán bộ giảng viên, sinh viên vi phạm quy chế thi. Những việc làm này có tác dụng hạn chế, ngăn chặn tình trạng sinh viên quay cóp, sử dụng tài liệu trong khi thi, đảm bảo được sự công bằng, kích thích được sự hứng thú trong học tập của sinh viên nói chung và tự học nói riêng.

- Chấm thi vô tư, công bằng, đánh giá đúng chất lượng bài thi có tác dụng củng cố niềm tin của sinh viên đối với thầy - cô giáo, và khuyến khích sinh viên chăm lo việc học tập hơn. Đối với những bài thi, kiểm tra học kỳ cần phải được rọc phách, được chấm hai vòng độc lập thực sự tại văn phòng. Trong quá trình tổ chức chấm thi ban chủ nhiệm khoa cần quản lý, giám sát chặt chẽ để tránh tình trạng chỉ có một giáo viên chấm rồi đổi bài cho giáo viên kia chỉ có ký và coi đó là chấm 2 vòng độc lập. Khi tổ chức thi xong, có thể công khai biểu điểm và bài thi, để sinh viên có cơ hội tự đánh giá bài làm của mình, tự đánh giá bài của bạn và cũng buộc giảng viên phải chấm bài nghiêm túc hơn, hạn chế được những tiêu cực trong qua trình chấm thi.

\section{Kết luận}

Kiểm tra, đánh giá kết quả học tập của sinh viên khép lại một quá trình dạy học, đồng thời cũng tạo ra sự khởi đầu của một quá trình dạy học mới. Do vậy cần tăng cường quản lý công tác kiểm tra đánh giá kết quả học tập của sinh viên nhằm giúp sinh viên cố gắng thường xuyên, chủ động, tích cực, sáng tạo, tự tin trong học tâp; thúc đẩy hoạt động tự học, hình thành thói quen và kỹ năng tự học; từ đó nâng cao năng lực tự học cho bản thân.

\section{TÀI LIỆU THAM KHẢO}

1. Phạm Thị Cúc (2001), Một số biện pháp quản lý nhằm nâng cao năng lưc tụ học cho sinh viên truờng Cao đẳng Su pham Kon Tum;

2. Hồ Ngọc Đại (2007), Giải pháp giáo dục, Nxb Hà Nội;

3. Lê Thanh Gia (2010), Đổi mói kiểm tra đánh giá là động lưc của đổi mói phuong pháp dạy học;

4. Trần Trọng Quế, Đổi mói kiểm tra, thi để nâng cao chất luợng đào tạo ở Truoờng Chính trị Nghệ An. 